\title{
Phylogenetic systematics of Hoya (Apocynaceae)
}

\author{
L. Wanntorp ${ }^{1}$
}

\section{Key words}

Acanthostemma

core Hoya

Eriostemma

Hoya

molecular systematics

New Guinean/Australian clade

phylogenetic tree

\begin{abstract}
Abstact Hoya with perhaps 300 species is one of the most diverse angiosperm genera in the tropical rainforests of Southeast Asia and New Guinea. Knowledge of the number of species and their relationships is still very unsatisfactory. Floral characters have been used to subdivide the genus into sections, although none of these groups were based on phylogenetic relationships. Recently, molecular phylogenetic studies have shed new light on the intrageneric relationships of the genus by identifying three main monophyletic clades, in addition to a core Hoya group that includes most of the species examined. One clade includes New Guinean/Australian species, while the other two, the Acanthostemma and the Eriostemma clades, mainly correspond to existing sections. I here discuss the phylogenetic findings in the light of the traditional morphological classifications, as a first step towards a new classification of Hoya based on phylogenetic relationships.
\end{abstract}

Published on 30 October 2009

\section{INTRODUCTION}

The genus Hoya of the family Apocynaceae includes 200-300 species distributed from India to the Pacific Islands (Fig. 1). The species are mostly epiphytic climbers with succulent leaves, inhabiting the tropical rainforest. The spectacular flowers are clustered in pseudoumbelliform inflorescences that are either concave and positively geotropic, convex and positively geotropic, or convex and negatively geotropic (Rintz 1978). The pentamerous corollas vary extensively in shape and size, from revolute over salver-shaped to urceolate and even tubular. Hoya flowers have staminal coronas consisting of five more or less erect lobes. The basal parts of the anther margins are mostly fused and form an 'anther skirt', a structure that has a nectariferous function (Kunze \& Wanntorp in press). The dorsal margins of the pollinia are generally provided with a crest, termed 'pellucid margin'. The presence of the anther skirt and of pellucid margins on the pollinia seem to be unique to Hoya in the tribe Marsdenieae. Fruits in Hoya are follicles that enclose narrow, spindle-shaped seeds without conspicuous wings (Omlor 1998).
The number of taxa described within Hoya probably greatly exceeds the real diversity in the genus and there are over 500 names of taxa listed in The Index of Plant Names (1999). This indicates the problems in the taxonomy of the genus, which is badly in need of revision. Despite several recent attempts from the horticultural world to divide the genus into sections using mainly leaf and flower characters (e.g., Burton 1985, 1995, 1996, Kloppenburg 1993, 2001), we still have to go back to the past to find available scientific classifications. The first classification was proposed by Hooker (1885) who divided the genus into the four sections: Crytoceras Hook.f. (= CyrtocerasBenn. in Schumann 1895), Pterostelma Wight, Ancistrostemma Hook.f. and Euhoya Miq. (by today's nomenclatural rules, the last becomes sect. Hoya). In 1913, Schlechter proposed five new sections. Sections Eriostemma Schltr., Oreostemma Schltr., Otostemma (Blume) Schltr., Physostelma (Wight) Schltr. and Plocostemma (Blume) Schltr., were mainly based on flower morphology and geographic distribution of the species. In 1916, Schlechter completed his classification by describing sect. Peltostemma.

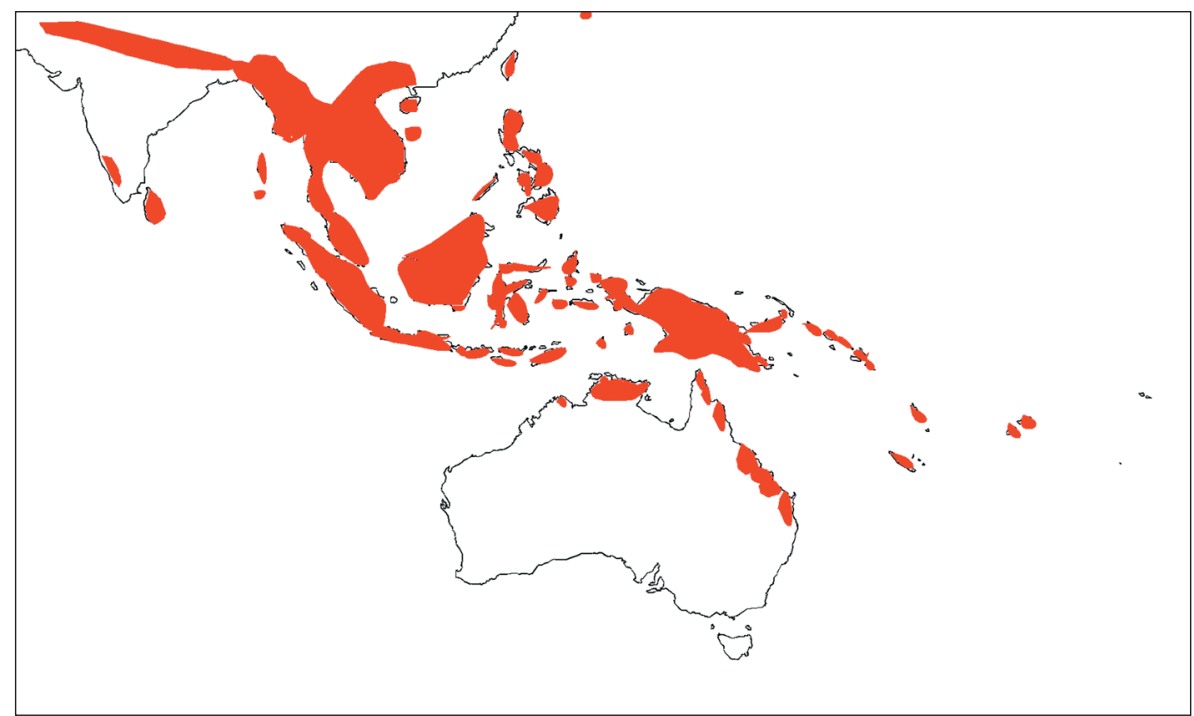

Swedish Museum of Natural History, Department of Phanerogamic Botany,

Fig. 1 Distribution of Hoya (redrawn from Wanntorp et al. 2006b).

Svante Arrhenius väg 7, P.O. Box 50007, SE-104 05 Stockholm, Sweden.

(c) 2009 Nationaal Herbarium Nederland

You are free to share - to copy, distribute and transmit the work, under the following conditions:

Attribution: $\quad$ You must attribute the work in the manner specified by the author or licensor (but not in any way that suggests that they endorse you or your use of the work).

Non-commercial: You may not use this work for commercial purposes.

No derivative works: You may not alter, transform, or build upon this work.

For any reuse or distribution, you must make clear to others the license terms of this work, which can be found at http://creativecommons.org/licenses/by-nc-nd/3.0/legalcode. Any of the above conditions can be waived if you get permission from the copyright holder. Nothing in this license impairs or restricts the author's moral rights. 


\section{CLASSIFICATION}

\section{New classifications should be based on monophyletic groups}

Today, systematists agree that classification should be based on monophyletic groups so as to reflect the true phylogenetic relationships between organisms. Taxa recognized in older classifications may, however, often conform to phylogenetic systematics, demonstrating the validity of many morphological characters used in the past. Molecular phylogenetic studies, based on chloroplast and nuclear gene sequences, were recently started in order to clarify intrageneric relationships in Hoya (Wanntorp et al. 2006a, b) as a first step towards a new phylogenetic classification of the genus. Aims of this paper are to discuss the topology of the phylogenetic tree (Fig. 2) obtained in Wanntorp et al. (2006b) in light of Schlechter's traditional classification $(1913,1916)$, and to list possible contradictions found between the molecular and the morphological approaches.

The phylogenetic tree in Wanntorp et al. (2006b) was not fully resolved showing that the molecular markers used were not informative enough to resolve all relationships in Hoya. Three main monophyletic clades were, however, clearly identified in the phylogenetic tree, in addition to a main group, the core Hoya group, and several species whose exact phylogenetic positions are not yet identified. Below, I discuss each of these clades and compare the molecular phylogenetic results to what previously known on the species included in each clade.

\section{The Acanthostemma clade}

In 1848, Blume established the genus Acanthostemma for species of Hoya having the following flower characters: hairy corolla lobes that are completely revolute so as to make the flowers appear round or globular in shape (Fig. 3a); coronas with outer lobes ending in two lateral extensions turning inwards on each other and forming conspicuous anther skirts (Wanntorp \& Forster 2007). Pollinaria of Acanthostemma species have obliquely elongate pollinia, with pellucid margins that extend along almost the entire dorsal edge, rhomboid and thick corpuscula with narrowly winged adhesive pads basally, and broadly winged caudicles (Wanntorp 2007) (Fig. 3b). Later on, Acanthostemma was lumped with Hoya and the name was subsequently used to delimitate a section in that genus (Kloppenburg 1993). The molecular analysis identified $H$. kentiana, $H$. 'tsangii', $H$. 'gracilis', and H. bilobata (Wanntorp et al. 2006b) as part of the Acanthostemma clade, showing a general agreement with the previously described section (Fig. 2). Another species, H. heuschkeliana, relatively newly described in the genus (Meve 2001), was nested in the Acanthostemma clade (Wanntorp et. al. 2006b) (Fig. 3c). The close affinity of $H$. heuschkeliana to Acanthostemma was already suggested by Kloppenburg (1993) on basis of morphology. Despite having corollas of urceolate or pseudourceolate shape, unusual in Hoya, $H$. heuschkeliana has other characters in common with Acanthostemma, such as pollinia with broadly winged caudicles.

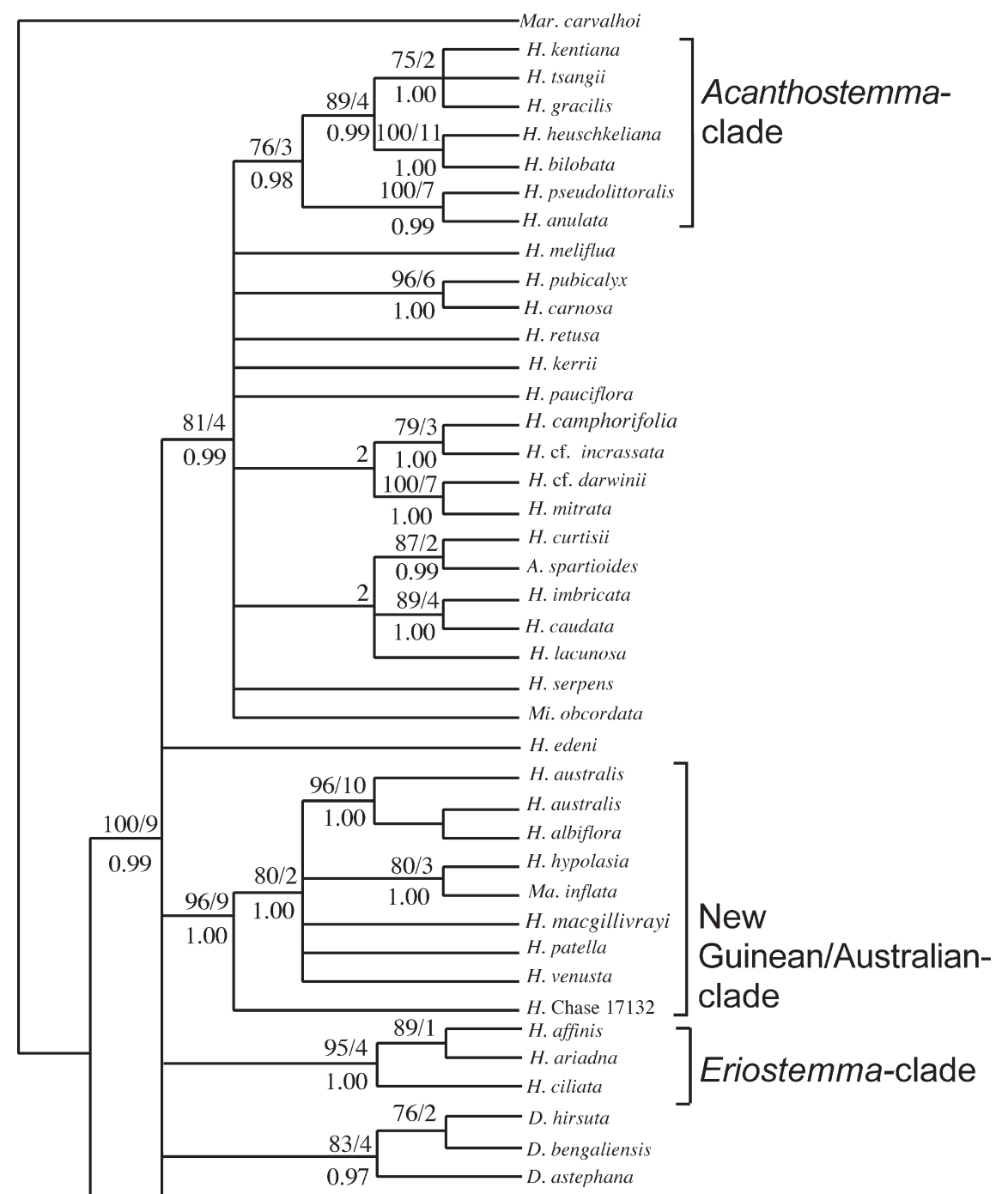

Fig. 2 Molecular phylogenetic tree of Hoya based on trnL-F region, atpB-rbcL spacer and nuclear ITS sequences (redrawn after Wanntorp et al. 2006b). 

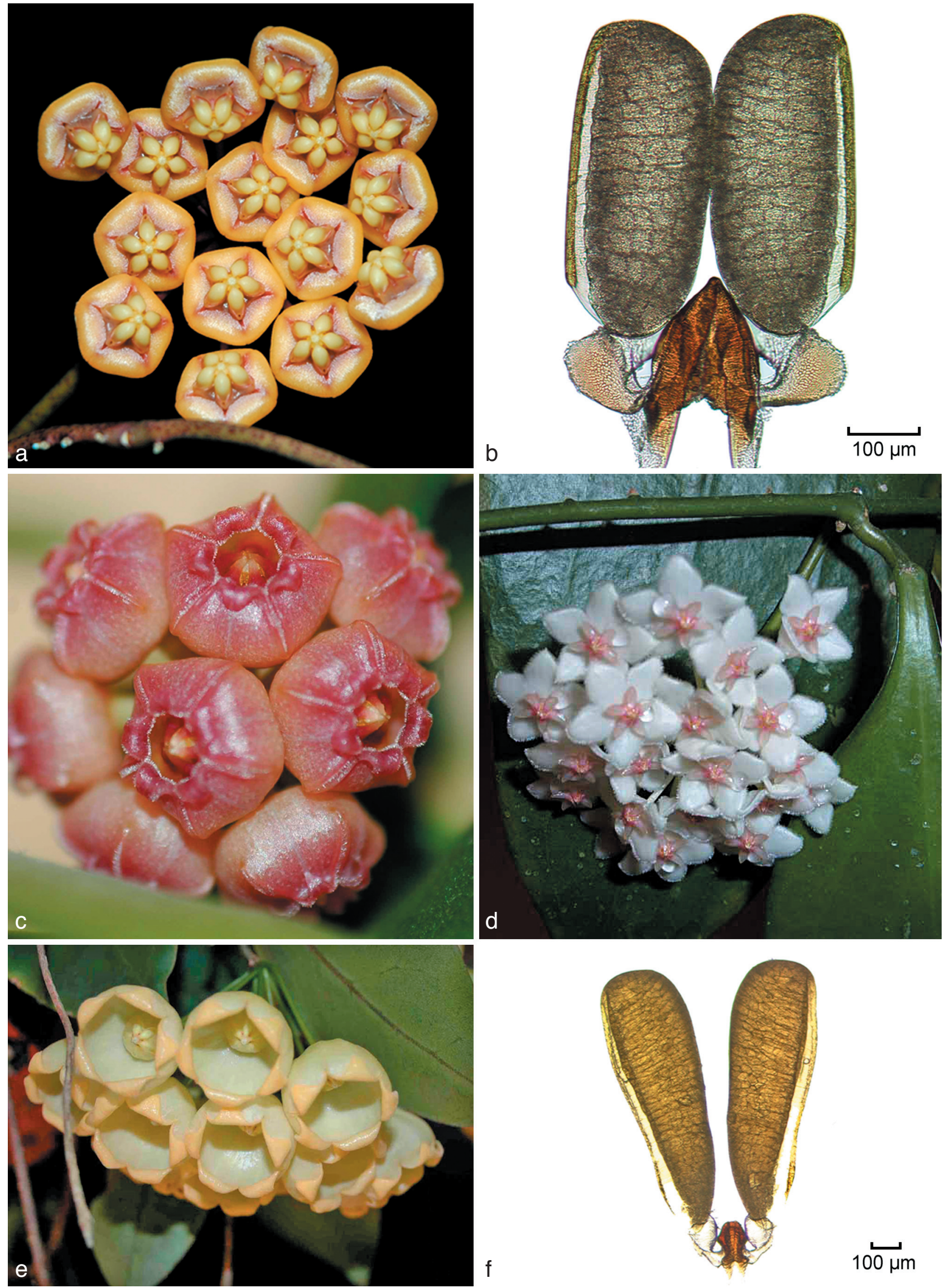

Fig. 3 a-d. Acanthostemma clade. a. Hoya kloppenburgii; b. H. 'gracilis', pollinarium with broadly winged caudicles and pollinia with pellucid margins; c. H. heuschkeliana; d. H. pseudolittoralis. - e, f. The New Guinean/Australian clade. e. H. inflata; f. H. hypolasia, pollinarium showing pollinia slightly protuding outwards. Photos: a, c by A. Boström; d by A. Gustavsson; e by D. Liddle. 

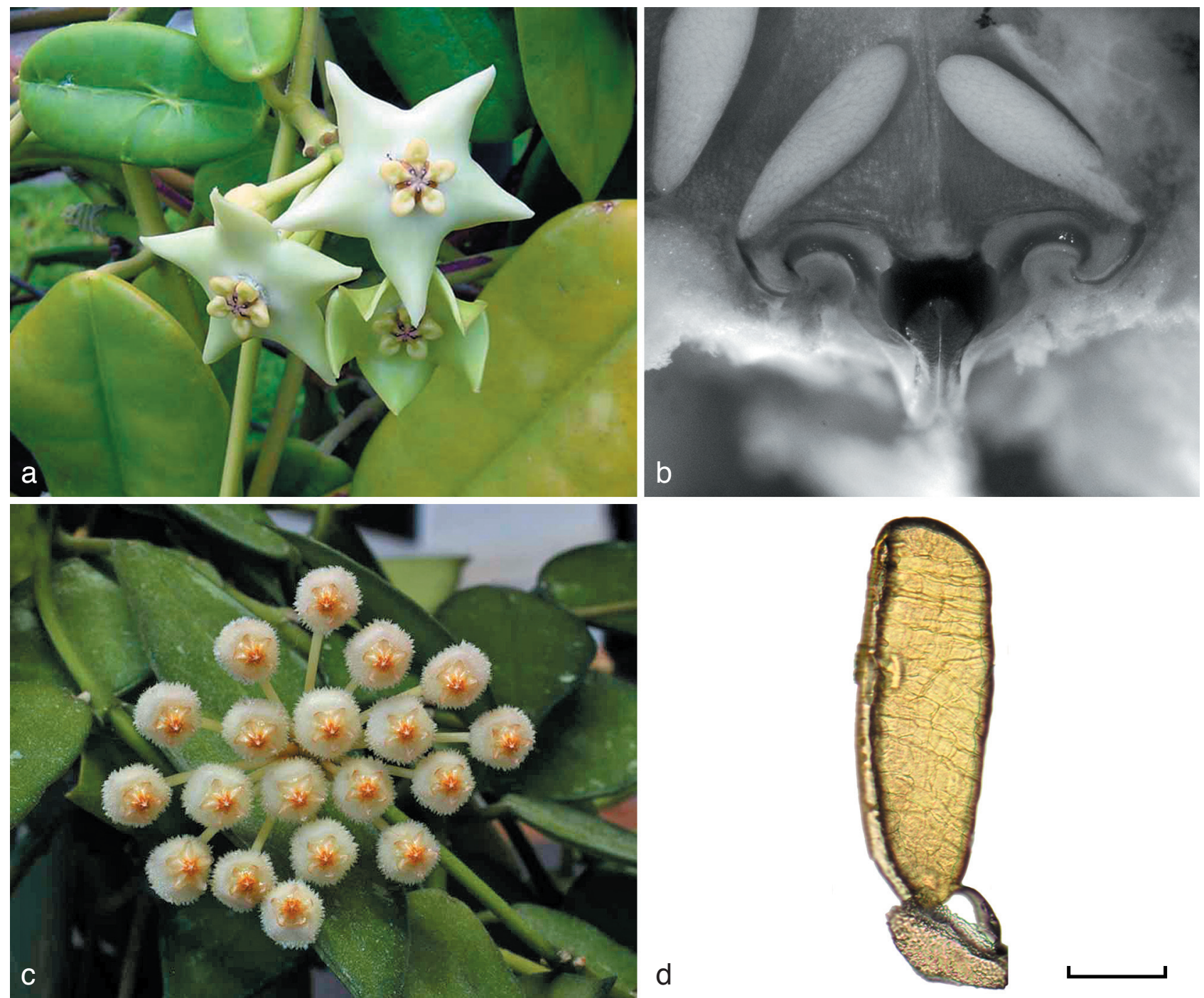

Fig. 4 a, b. The Eriostemma clade, H. coronaria. a. Habit; b. pollinarium with twisted caudicles and pollinia without pellucid margins. - c, d. The core Hoya group, $H$. lacunosa. c. Habit; d. pollinium with broadly winged caudicle. Photos a, c by T. Nyhuus; b by H. Kunze.

An unexpected result was the position of $H$. pseudolittoralis $(=H$. anulata) (Fig. $3 d$ ), as sister to the remaining species of the Acanthostemma clade. Hoya pseudolittoralis is the single species from New Guinea among those examined, that was not found clustered in the New Guinean/Australian clade (see below and Fig. 2) (Wanntorp et al. 2006b). Hoya pseudolittoralis was originally put in Schlechter's species-rich sect. Euhoya (1913). Its salver-shaped corollas and its inconspicuous anther skirts do not support a close relationship to the Acanthostemma species. Hoya pseudolittoralis has, however, pollinia with broadly winged caudicles that are very similar in morphology to the pollinia of species of Acanthostemma, thus possibly supporting the position found in the molecular phylogenetic tree (Wanntorp et al. 2006b).

\section{The New Guinean/Australian clade}

Only eight species of Hoya are endemic to Australia (Forster \& Liddle 1996) while New Guinea seems to be one of the main centres of diversity for the genus, and Forster (1996) lists not less than 74 species from that area. The New Guinean species $H$. hypolasia, $H$. inflata (Fig. $3 e$ ), $H$. patella, $H$. venusta, and an undetermined taxon ( $H$. spec. Chase 17132), as well as the Australian $H$. albiflora, $H$. australis and $H$. macgillivrayi were found together in a well-supported monophyletic clade in the tree (Wanntorp et al. 2006b) (Fig. 2). A sister relationship between taxa from New Guinea and taxa from Australia is concordant with the results of other phylogenetic studies and is consistent with the fact that New Guinea and Australia lie on the same continental plate (McLoughlin 2001), and taxa from these two areas are often found to be closely related (e.g., Linder \& Crisp 1995, Wanntorp \& Wanntorp 2003). The species of Hoya examined have large flowers with bell-shaped corollas (Fig. $3 \mathrm{e}$ ), pollinaria with obovate pollinia, that are protruding outwards basally and thick rhomboid corpuscula (Fig. 3f). Hoya inflata (Fig. $3 \mathrm{e}$ ) was originally described as the single species in the genus Madangia but phylogenetic analyses based on molecular as well as morphological characters have shown that the genus has to be included in Hoya (Wanntorp et al. 2006a, b, Wanntorp \& Forster 2007). The other species examined were previously ascribed to three different sections by Schlechter (1913). Hoya macgillivrayi, H. patella and $H$. venusta were placed in sect. Physostelma, $\mathrm{H}$. hypolasia in sect. Plocostemma, while $H$. albiflora and $H$. australis were included in sect. Pterostelma. According to the molecular phylogenetic studies, these three sections have to be merged, although molecular and morphological phylogenetic studies of several species from New Guinea and Australia are necessary in order to confirm this result.

\section{The Eriostemma clade}

Hoya affinis, $H$. ariadna and $H$. ciliata are three of the eleven species traditionally grouped in sect. Eriostemma (Schlechter 1913). These three species formed a distinct clade in the molecular phylogenetic tree (Wanntorp et al. 2006b) (Fig. 2). Also in 
this case, there seems to be agreement between traditional and modern systematics. Eriostemma species are characterised by a terrestrial (not epiphytic) habit and flowers with small coronas lying above large salver-shaped pubescent corollas (Fig. 4a). The club-shaped pollinia lack pellucid margins and have twisted and winged caudicles (Fig. 4b). Altogether this morphology well defines sect. Eriostemma and supports the molecular results. Kloppenburg \& Gilding (2001) even suggested that Eriostemma should be excluded from Hoya, based on the morphological characters listed above. Although it cannot be ruled out, this suggestion does not yet find enough support in the molecular analyses (Fig. 2) (Wanntorp et al. 2006b).

\section{The core Hoya group}

Many of the species of Hoya examined were found as part of a large core Hoya group in the phylogenetic tree of Wanntorp et al. (2006b). This group includes several of the species originally listed in Schlechter's sect. Euhoya. The exact relationships of several of these species were, however, not retrieved and further molecular studies are needed to resolve the present polytomies (Wanntorp in prep.). An example of species in the core Hoya clade whose position in the tree is especially intriguing is the commonly cultivated $H$. lacunosa (Fig. 4c, d), which is one of the species of Hoya appreciated for the sweet smell of their flowers. Hoya lacunosa has flowers very similar to those of the Acanthostemma species, with hairy corolla and revolute lobes (Fig. 4c), and pollinia with broadly winged caudicles (Fig. 4d). This species has, however, conspicuous anther skirts, which are not typical for the Acanthostemma species, thus supporting a position for $H$. lacunosa outside the Acanthostemma clade proper. In fact, morphological characters of the flowers of Hoya seem to have been switched on and off during the evolution of the different species, and it is difficult to point out specific morphological characters as phylogenetically informative throughout the genus. This should, however, not hinder the study of morphological characters and their use in combination with molecular data.

\section{CONCLUDING REMARKS AND FUTURE STUDIES}

The molecular phylogenetic results have shown that several traditional sections, such as Acanthostemma and Eriostemma (Schlechter 1913, 1916, Hooker 1885) are in fact reflecting true relationship between the species that they include. Other sections, such as Physostelma, Plocostemma and Pterostelma will probably have to be revised in order to mirror monophyletic groups in Hoya. We are only at the beginning of the examination of the phylogenetic relationships within Hoya. We have not yet analysed the positions of all species of this genus and there are still sections such as Peltostemma (Schlechter 1916) and Ancistrostemma (Hooker 1885) that have not yet been examined in light of the molecular phylogenetic tree. It is also indispensable to go on with $\alpha$-taxonomic studies of Hoya in parallel with the phylogenetic studies. Taxonomic revisions of groups of Hoya, are, at the moment, in progress in many Southeast Asian areas where Hoya occurs and will be very important to interpret the phylogenetic results. Traditional taxonomy, molecular data as well as the use of a phylogenetic approach will together form the base of a new classification of a dominant but poorly understood genus of Southeast Asia.
Acknowledgements Many thanks to the organizing committee of the Flora Malesiana for organizing such an interesting meeting, and for giving me the possibility to present some of my latest results on Hoya. I also like to thank the Royal Academy of Sciences (KVA), Stockholm for supporting my trip to Leiden and my participation to the meeting and to Torill Nyhuus, A. Boström, D. Liddle, and Dr. H. Kunze for help with some of the photographs in the paper.

\section{REFERENCES}

Blume CL. 1848. Rumphia 4: 49-50. Sulpke, Lugduni Batavorum. Burton CM. 1985. Hoya sections. The Hoyan 7: 36-37.

Burton CM. 1995. A tentative alternative arrangement of Hoya sections. The Hoyan 17: 1-12.

Burton CM. 1996. A tentative alternative arrangement of Hoya sections. The Hoyan 18: 1.

Forster PI. 1996. A checklist of the Asclepiadaceae of Papuasia. Science in New Guinea 22: 15-22.

Forster PI, Liddle DJ. 1996. In: Orchard A (ed), Flora of Australia. CSIRO, Melbourne.

Hooker JD. 1885. Asclepiadeae. In: Hooker JD (ed), Flora of British India: 4, 1-78. Reeve \& Co, London.

Kloppenburg D. 1993. Hoya sections. Kloppenburg, Fresno, CA.

Kloppenburg D. 2001. Hoya sections - A complete study. Revised October 2001. Privately published, Fresno.

Kloppenburg D, Gilding E. 2001. Eriostemma (Schlechter) Kloppenburg, Gilding. Fraterna 14: 1.

Kunze H, Wanntorp L. In press. Corona and anther skirt in Hoya (Apocynaceae, Marsdenieae). Plant Systematics and Evolution.

Linder PH, Crisp MD.1995. Nothofagus and Pacific biogeography. Cladistics 11: $5-32$.

Meve U. 2001. Hoya heuschkeliana, a neo-endemic of Mt. Balusan (Philippines, Luzon), and remarks on the urceolate flower type in Asclepiadoideaae. Asklepios 82: 7-10.

McLoughlin S. 2001. The breakup history of Gondwana and its impact on pre-Cenozoic floristic provincialism. Australian Journal of Botany 49: 271-300.

Omlor R. 1998. Generische Revision der Marsdenieae (Asclepiadaceae). PhD thesis, Münster University, Münster. Shaker Verlag, Aachen.

Rintz RE. 1978. The peninsular Malaysian species of Hoya (Asclepiadaceae). Malayan Nature Journal 30: 467-522.

Schlechter R. 1913. Die Asclepiadaceen von Deutsch-Neu-Guinea. Botanische Jahrbücher für Systematik, Pflanzengeschichte und Pflanzengeographie 50: 81-164.

Schlechter R. 1916. Neue Asclepiadaceen von Sumatra und Celebes. Beihefte zum Botanischen Centralblatt 34: 1-18.

Schumann K. 1895. Asclepiadaceae. In: Engler A, Prantl K (eds), Die natürlichen Pflanzenfamilien: 289-290. Engelmann, Leipzig.

The Plant Names Project. 1999. International Plant Names Index. Published on the internet: http://www.ipni.org.

Wanntorp L. 2007. Pollinaria of Hoya (Marsdenieae, Apocynaceae) - shedding light on molecular phylogenetics. Taxon 56: 465-478.

Wanntorp L, Forster PI. 2007. Phylogenetic relationships between Hoya and the monotypic genera Madangia, Absolmsia, Micholitzia (Marsdenieae, Apocynaceae): insights from flower morphology. Annals of the Missouri Botanical Garden 94: 36-55.

Wanntorp L, Kocyan A, Van Donkelaar R, Renner SS. 2006a. Towards a monophyletic Hoya (Marsdenieae, Apocynaceae): inferences from the chloroplast trnL region and the rbcL-atpB spacer. Systematic Botany 31 : 586-596.

Wanntorp L, Kocyan A, Renner SS. 2006b. Wax plants disentangled: a phylogeny of Hoya (Marsdenieae, Apocynaceae) inferred from nuclear and chloroplast DNAn sequences. Molecular Phylogenetics and Evolution 39: 722-733.

Wanntorp L, Wanntorp H-E. 2003. The biogeography of Gunnera L.: vicariance and dispersal. Journal of Biogeography 30: 1-9. 